\title{
"Chocolate City, Vanilla Suburbs:" Will the Trend toward Racially Separate Communities Continue?
}

\author{
Reynolds Farley, Howard Schuman, Suzanne Bianchi, \\ Diane Colasanto, and Shirley HatchetT
}

University of Michigan at Ann Arbor

\begin{abstract}
Almost a decade ago, the Kerner Commission warned that this country was moving toward two societies-one white and one black. Data on residential segregation indicate clear-cut boundaries for these two societies-large cities are becoming black but most suburban areas remain white. Detroit is a case in point and this led the 1976 Detroit Area Study to investigate the sources of racial residential segregation. Our approach was guided by three hypothesized causes of this segregation: (i) the economic status of blacks, (ii) the preference of blacks to be with their own kind, and (iii) the resistance of whites to residential integration. Ne developed several new measurement techniques and found that most evidence supported the third hypothesis. Blacks in the Detroit area can afford suburban housing and both blacks and whites are quite knowledgable about the housing market. Most black respondents expressed a preference for mixed neighborhoods and are willing to enter such areas. Whites, on the other hand, are reluctant to remain in neighborhoods where blacks are moving in and will not buy homes in already integrated areas. This last result has been overlooked by traditional measures of white attitudes toward residential integration but emerges clearly with the new measure.
\end{abstract}

\section{INTRODUCTION}

Almost a decade ago, the Kerner Commission warned that this country was moving toward two societies-one white and one black (U.S. National Advisory Commission on Civil Disorders, 1969, p. 407). Recent data on patterns of residential segregation in large metropolitan areas (Sørensen, Taeuber, and Hollingsworth, 1975; Long, 1975; U.S. Bureau of the Census, 1975, Table 1; Hermalin and Farley, 1973) confirm this prophecy and indicate clear-cut boundaries for these two societies-large cities are becoming black and suburban areas are remaining white.

The Detroit metropolitan area is a case in point. About $45 \%$ of the central city's 1.5 million residents were black in 1970 but only $4 \%$ of the 2.5 million suburban residents were black (U.S. Bureau of the Census,

This research was supported by National Science Foundation Grant SOC76-00768. The authors thank Karl Taeuber for his useful comments on earlier drafts of this paper. 
1971a, Table 24). Since 1970 , the city has become even more black. One indicator of this is the racial composition of the public schools. The proportion black in the city's schools rose from $64 \%$ in 1970 to $80 \%$ in 1976 (U.S. Office for Civil Rights, 1977). ' In essence, it appears Detroit is becoming a black city imbedded in a white suburban ring, or as a pop tune describes it: a "chocolate city with vanilla suburbs" (Malbix/Ricks Music, BMI, 1976).

This situation led us, as investigators for the 1976 Detroit Area Study (DAS) of the University of Michigan, to try to better understand the nature and causes of residential segregation in Detroit. We believe that our results may be generalized to many of the nation's large metropolises.

We began by examining the three most common explanations for racial residential segregation. One view contends that racial differences in economic status account for residential segregation. This is not a satisfactory explanation. In recent years, racial differences in education have narrowed and the income of blacks has risen slightly faster than that of whites (Levitan, Johnston, and Taggart, 1975). In the Detroit area, for example, the median income of black families as a proportion of that of families rose from $59 \%$ in 1959 to $69 \%$ in 1969 (U.S. Bureau of the Census. 1962, Tables 76 and 78, 1972a, Table 198). Despite these changes in the economic position of blacks, racial residential segregation in the Detroit area hardly decreased (Van Valey, Roof, and Wilcox, 1977, Table 1; Sørensen et al. 1975, Table 1).

Another explanation for residential segregation focuses upon the prejudices of whites. Over time, however, whites appear to have become much more willing to accept black neighbors. The proportion of whites in national samples who said that they would not be upset if a black with an income and education similar to their own moved onto their block rose from $35 \%$ in 1942 to $84 \%$ in 1972 (Sheatsley, 1966; National Opinion Research Center, 1972). Specifically, in the Detroit area, the proportion of whites saying they would not be disturbed if a black moved onto their block increased from $40 \%$ in 1958 to $79 \%$ in 1976 . Although white responses to these standard questions have changed greatly, there have not been concomitant reductions in residential segregation.

A third popular view contends that neighborhoods are segregated be-

${ }^{1}$ Another indication of the changing racial composition of the central city was obtained from the Census Bureau's March 1976 Current Population Survey (CPS). In 1970, the decennial census reported that $60 \%$ of the city's households and $96 \%$ of those in the suburbs were headed by whites. The 1976 CPS included a sample of 288 central city and 547 suburban households and found that $50 \%$ of the city and $96 \%$ of the suburban households were headed by whites. If we assume there are no design effects, the Standard Error of estimate for the proportion of household heads white in the city in 1976 is approximately $3 \%$ suggesting that the chances are two out of three that the true proportion white among household heads was between 47 and $53 \%$. 
cause blacks prefer to live with other blacks and not with whites. Evidence does not support this explanation. A variety of national and local studies reveal that blacks would rather live in racially mixed than in segregated neighborhoods (Pettigrew, 1973, pp. 43-58). Moreover, there has been an apparent increase in this preference in recent years. Between 1958 and 1971, the percentage of blacks in Detroit saying they preferred racially mixed areas rose from 56 to $62 \%$ (Duncan, Schuman, and Duncan, 1973, p. 108) and reached $83 \%$ in the 1976 study which we conducted.

Since these explanations, as tested in previous studies, do not account for the persistence of racially separate communities, our study of racial segregation included several innovations in measurement. We focused our concern on three specific topics.

Economic factors and knowledge of the housing market. We realize that economic variables do not account for residential segregation but we do not know how much information people have about the cost of housing and the financial capabilities of blacks. We wondered if blacks fail to seek suburban housing which they can afford because they overestimate its costs. We wondered if whites give liberal answers to the "Black on your block" question because they believed that very few blacks can actually afford homes in white areas. We also wished to determine if blacks and whites had similar ideas about which areas are attractive and if they share the same views of the hostility blacks would face if they moved into the suburbs.

The residential preferences of blacks. Most previous investigations of the neighborhood preferences of blacks have used one question asking whether it is desirable to live in mixed or segregated neighborhoods. This provides insufficient information about the nature of black preferences and thus we presented black respondents with diagrams representing varying degrees of interracial neighborhoods, asked their preferences, and then determined why they selected such neighborhoods. We assessed their willingness to move into neighborhoods of each type and, if they were unwilling to enter an all-black or all-white neighborhood, we asked why.

The residential preferences of whites. We believe that the "Black on your block" question which has traditionally been used in studies of the neighborhood prcferences of whites, provides too little information. As Levine noted, it does not assess how whites would react in a variety of real and potential settings and does not assist in understanding a complex issue (Levine, 1971/72, p. 577). We presented white respondents with diagrams of a number of neighborhoods with different interracial mixtures. We asked if they would be uncomfortable in each of the neighborhoods and, if so, would they try to move away and why. We also determined their willingness to purchase a home in a racially mixed neighborhood. 
Data were gathered in the spring and summer of 1976. The target population consisted of heads or coheads of households who lived in year-round housing units in the Detroit area in April to July of 1976. The DAS sample consisted of two components. One was a two-stage probability sample of housing units drawn from the three-county Detroit Standard Metropolitan Statistical Area (SMSA). The second component was an additional probability sample of housing units occupied by blacks and located within central city census tracts at least $15 \%$ black in 1970. The purpose of this supplement was to increase the number of blacks available for analysis (Bianchi, 1976). ${ }^{2}$

A total of 1503 sample households was drawn from which 1134 interviews were obtained from one person per household, either the head or spouse of head, chosen by a random process in multiperson households. A total of 734 whites and 400 blacks were interviewed, yielding response rates of 77.9 and $71.3 \%$, respectively. Race of interviewer was controlled such that black respondents were always interviewed by blacks; white respondents, by white interviewers.

The geographic distribution of the sample mirrored that of the atea. Eighty-five percent of 734 white respondents lived within the Detroit suburbs but only 11 of the 400 blacks were suburban residents. The mean age of respondents in the DAS was 45 years for whites and 43 years for blacks. On the average white household heads or their spouses completed 12.1 years of school while blacks completed about 1 year less. Median household income was about $\$ 18,500$ for whites and $\$ 12,500$ for blacks. Income levels are relatively high in Detroit and thus the average income of white households in the Detroit area exceeds the national average by about $\$ 4,000$ while among blacks the Detroit advantage is $\$ 2,500$.

We wished to determine if our sample overrepresented some groups of the population and underrepresented others. Fortunately, we were able to compare the demographic characteristics of DAS respondents to those of residents included in the Census Bureau's March, 1976, Current Population Survey. Table 1 presents these findings and indicates that the DAS sample and that of the Census Bureau are very similar with regard to age, educational attainment, sex of household heads, and income. Excluding the supplemental sample of blacks we found that $18 \%$ of the household heads or their spouses were black while the Census Bureau's CPS found that $19 \%$ were black which suggests our sample did not underrepresent blacks.

2 Of the 400 black respondents, 358 were in the area covered by the additional probability sample. Data presented in this paper are not weighted for the disproportionate sampling of blacks who lived in predominantly black census tracts. We experimented with the use of both weighted and unweighted data for blacks and concluded that the use of weights did not significantly alter our findings. 


\section{ECONOMIC FACTORS AND KNOWLEDGE OF THE HOUSING MARKET}

To determine what knowledge people have about the housing market, we selected one area from the central city and four of the largest suburbs; colored each distinctively on a map of the Detroit SMSA (see Fig. 1) and asked several questions about each area. If race were not salient in the selection of housing, we expect that many whites would like to live in the northwest area of the central city and that many blacks would live in the suburbs. The locations have very different reputations but in each area the dwelling units are primarily single family homes. The locations we selected were the following.

\section{Housing Locations}

Northwest Detroit central city. This is the area within the city which has the most desirable and expensive homes. A large fraction of them were built in the 1920s but there was substantial construction in this area following World War II. This section of the city is quite far removed from

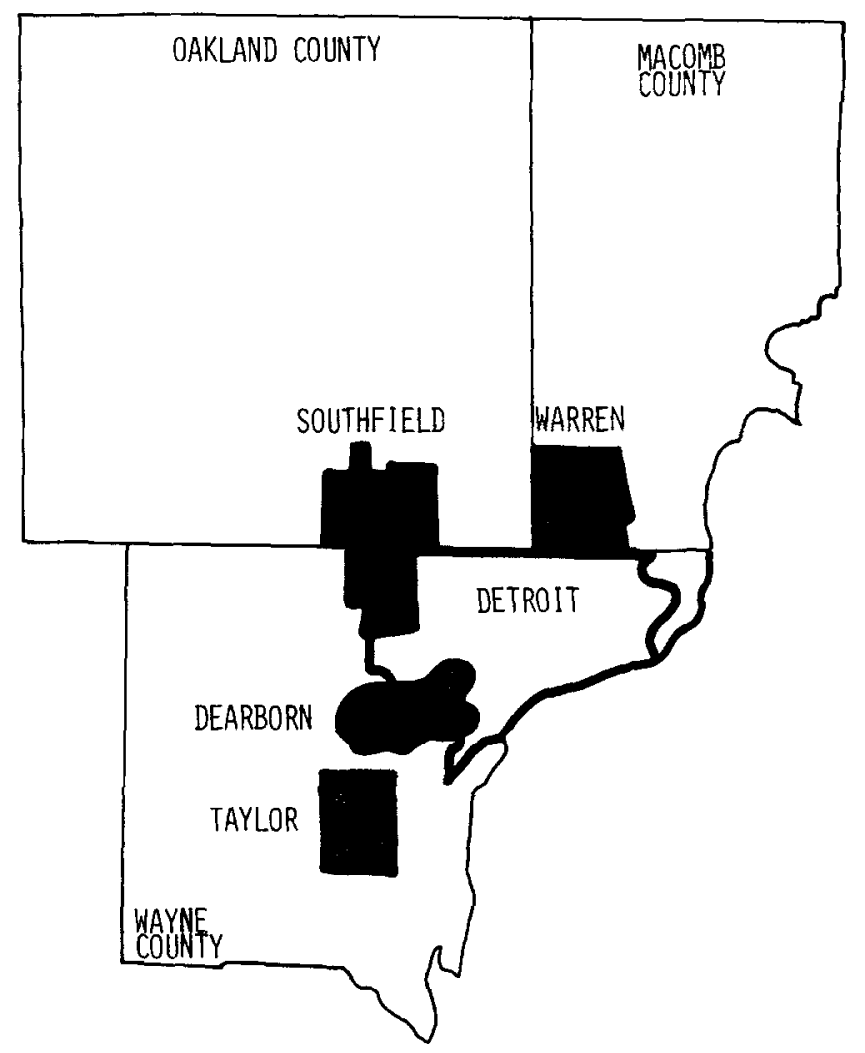

FIG. 1. Map of the metropolitan Detroit area. 


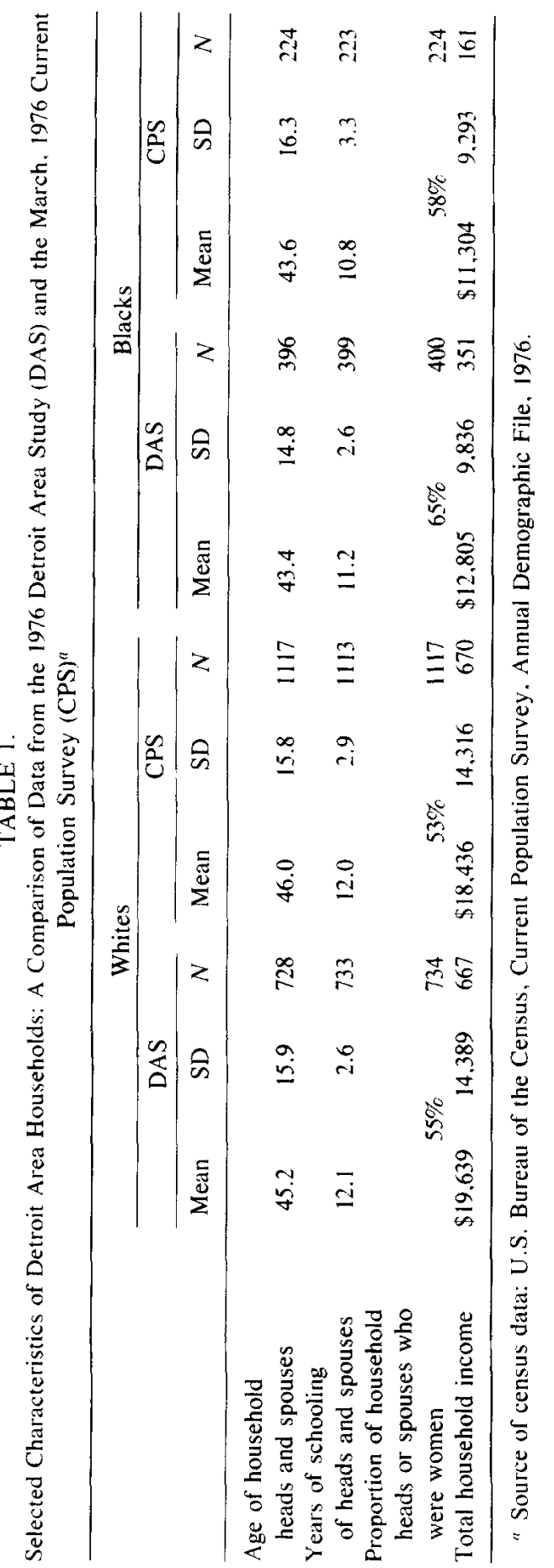


the deteriorating inner core where crime rates are presumed to be much higher. Through the 1960s, this section of the city was almost exclusively white. During the 1970s, blacks entered but when the Census of 1970 was conducted, $99.14 \%$ of the residents were still white (U.S. Bureau of the Census, 1972b, Table P-1) though there has probably been noticeable change since then.

Southfield. This large suburb shares a common boundary with the central city. It is primarily a dormitory suburb of expensive single family homes and the average value of a house in $1970-\$ 36,000$ - was almost double the average for the entire metropolis. Our survey results supported our belief that this suburb does not have a reputation for being antiblack although in 1970 only 100 of its 69,000 residents were black (U.S. Bureau of the Census, 1971b, Table 24).

Warren. This is a large industrial and residential suburb which also shares a common boundary with Detroit. The average value of homes$\$ 23,000$ in 1970 -was typical for the suburban ring. This suburb has a reputation for hostility to blacks and, in 1970 , only 120 of its 180,000 inhabitants were black (U.S. Bureau of the Census, 1971b, Table 24). However more than 5000 central city black residents were working at jobs within Warren in 1970 (U.S. Bureau of the Census, 1973, Table 2).

Dearborn. This suburb is surrounded on three sides by sections of the city of Detroit that are largely black. Houses in this suburb are also about average in value for the suburban ring- $\$ 22,000$ in 1970. It is the home of the Ford Motor Company and about 79,000 people-including 11,000 central city blacks-worked in its shops and offices (U.S. Bureau of the Census, 1973, Tables 1 and 2). Dearborn has a reputation as being vigorously antiblack and several of our respondents assured us that so long as Mr. Hubbard remained mayor, no black would live within this suburb. In 1970 , the census found only 13 blacks among the suburb's 104,000 residents (U.S. Bureau of the Census, 1971b, Table 24).

Taylor. Among the major Detroit suburbs, Taylor is the one with the least expensive homes. They averaged about $\$ 19,000$ in 1970 . This is not an area of employment but it is surrounded by the metropolitan airport and several unattractive industrial complexes. This suburb does not have a reputation for unusual hostility to blacks but, in 1970 , only 20 of its 70,000 residents were black (U.S. Bureau of the Census, $1971 \mathrm{~b}$, Table 24).

\section{Housing Costs}

We first wished to learn if blacks and whites accurately knew the cost of housing in these areas. We asked respondents their estimates of the average cost of homes in each area, and then asked them whether they thought that only a few, about half, many, or almost all black families in the Detroit area could afford to live within the designated area. We compare in Table 2 our best estimate of the true cost of a single family 
TABLE 2

The Cost of Housing in the Detroit Area

\begin{tabular}{|c|c|c|c|c|c|}
\hline \multirow[t]{3}{*}{ Area } & \multirow{3}{*}{$\begin{array}{l}\text { Estimated } \\
\text { true cost } \\
\text { of a home } \\
\text { in } 1976\end{array}$} & \multicolumn{4}{|c|}{ Cost $\$$ of an average home as estimated by } \\
\hline & & \multicolumn{2}{|c|}{ White respondents } & \multicolumn{2}{|c|}{ Black respondents } \\
\hline & & Mean & SD & Mean & $\mathrm{SD}$ \\
\hline $\begin{array}{l}\text { Northwest Detroit } \\
\text { central city }\end{array}$ & $\$ 25,400$ & $\$ 24,300$ & $\$ 8,600$ & $\$ 26,900$ & $\$ 8,500$ \\
\hline Southfield & 60,000 & 41,700 & 11,400 & 39,900 & 14,500 \\
\hline Warren & 38,900 & 34,100 & 9,000 & 30,100 & 12,800 \\
\hline Dearborn & 38,000 & 38,100 & 10,100 & 34,700 & 15,400 \\
\hline Taylor & 31,100 & 29,400 & 9,000 & 30,900 & 14,000 \\
\hline
\end{tabular}

home in each area in 1976 with the mean estimate of black and white respondents. The "true estimates" were developed from tabulations of the 1970 Census of Housing and the 1974 Annual Housing Survey. This survey, conducted by the Bureau of the Census, gathered data about housing costs and conditions from 15,000 Detroit area households (U.S. Bureau of the Census, 1972b, Table H-1, 1976, Tables B-1, B-4, C-1, and C-4). Housing prices have been adjusted for inflation.

Both blacks and whites are quite knowledgable about the costs of housing. They correctly differentiate the suburbs and perceive that suburban housing is least expensive in Taylor and most costly in Southfield. In general, the average estimates of blacks and whites are similar for each of the locations. The standard deviations of the estimates of suburban housing costs of black respondents are considerably larger than those of whites perhaps reflecting a lack of familiarity with the suburban housing market on the part of blacks. The most serious mistake is the tendency of both races to substantially underestimate housing prices in Southfield. We conclude that blacks do not overestimate suburban housing costs and they accurately identify variations in the prices of suburban housing.

Do whites and blacks believe that many black families can afford to live within these areas? Figure 2 shows the proportions of respondents who think that at least one-half of the Detroit area black families can afford to live in each location. There is a major city-suburban difference and about $90 \%$ of the respondents-white and black - believe that most blacks can afford the northwest section of the central city. Thus there is consensus that central city housing is within the price range of Detroit blacks.

However, respondents perceived differences in the ability of blacks to afford homes in various suburbs. More than half the white and black respondents thought that most black families could pay for housing in two of the least expensive suburbs: Taylor and Warren. When considering the 

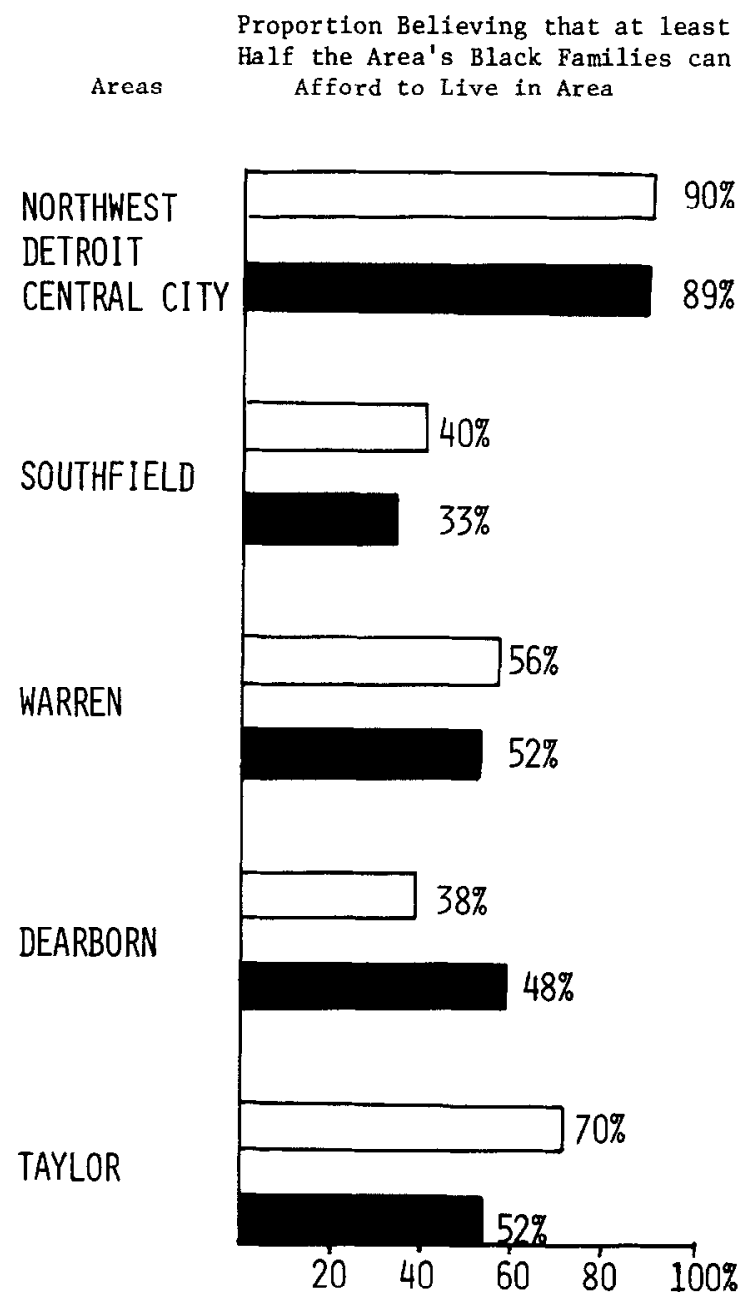

Fig. 2. Proportion of Detroit area whites (clear bar) and blacks (dark bar) believing that at least half the area's black families can afford to live in specific areas.

other suburbs, Southfield and Dearborn, respondents believed that fewer blacks could afford homes in these locations, though even in these cases at least a third of each racial group saw the suburb as financially accessible to half or more of the black population.

These data suggest that blacks are quite well informed about suburban housing costs and thus we reject the hypothesis that one reason blacks do not live in the suburbs is that they believe that all suburban housing is very expensive and therefore do not seek it. Blacks realize that the majority of blacks can afford to live in several of the suburbs we considered and Detroit area whites are also cognizant of the financial capabilities 
of blacks. We infer that whites understand that the absence of blacks from the suburbs is not due to blacks being unable to afford suburban housing.

\section{DO BLACKS WISH TO LIVE IN RACIALLY MIXED NEIGHBORHOODS?}

Previous studies (for a summary see Pettigrew, 1973, pp. 43-58) found that a majority of blacks expressed a general preference for integrated neighborhoods. To analyze more adequately the nature of these preferences, we developed a graphic measure that provided black respondents with five diagrams of neighborhoods (see Fig. 3). Each diagram shows 15 homes but the racial composition of the neighborhoods varies from one diagram to the next. We asked respondents to imagine that they are looking for a house and have found one that they can afford. This house is designated as the center of each of the neighborhoods pictured. In the first card, all 14 other homes are occupied by blacks; while the fifth card represents a neighborhood which contains no black families. The other three cards show intermediate mixtures, as indicated in Fig. 3.

Black respondents were asked to rank the neighborhoods from the one most attractive to them through the neighborhood that was least attractive. The left panel of Fig. 4 reports these evaluations. We indicate the proportion of blacks who said the specific neighborhood was either their first or second choice. A very clear preference pattern emerged. Sixtytwo percent selected the half-black half-white neighborhood as their first choice and another $20 \%$ of the black respondents said it was their second choice. The second most popular was the area containing ten black and four white families. 'The neighborhoods with either two blacks or all blacks were favored by much lower percentages. The strongest aversion was to the all-white neighborhood since only $5 \%$ placed it first and $63 \%$ ranked it as the least attractive area.

Respondents were asked to consider further the one neighborhood they found most attractive. Using an open-ended question we asked them to explain why they found it so. We anticipated that those choosing the 50/50 neighborhood would often state that city services were better or that physical conditions were more attractive in integrated areas, but only one-quarter of the black respondents gave these as their primary reason for wanting to live in mixed neighborhoods. The most frequently espoused view had to do with getting along with whites. About two-thirds of those who preferred the $50 / 50$ area gave reasons such as: "When you have different kinds of people around, children understand better," "I'd like my children to know different kinds of people," "I'd rather live in a neighborhood that is mixed-don't have any trouble, no hostility," "It might make it better to get along with white people." These results corroborate earlier findings which show that a majority of black respondents not only favor residential integration but they do so because of a belief in racial harmony rather than a belief that services are better in mixed neighborhoods (Campbell and Schuman, 1968, p. 16). 
RACIALLY SEPARATE COMMUNITIES

市

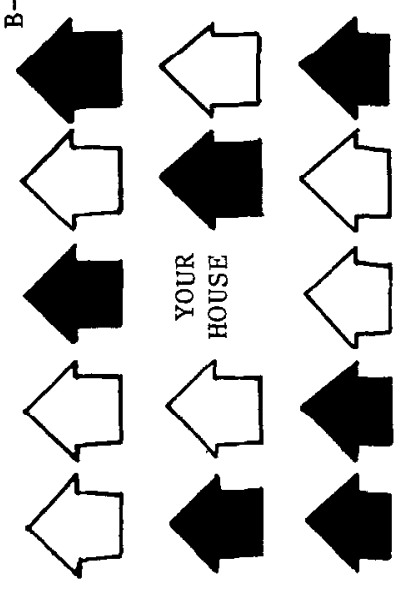

$\mathfrak{1}$
1
0

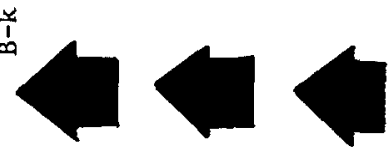

乐

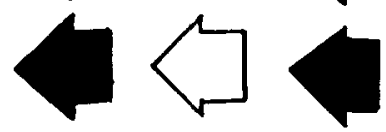

象焉

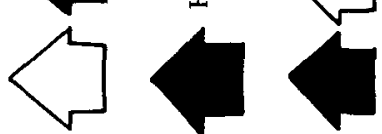

p
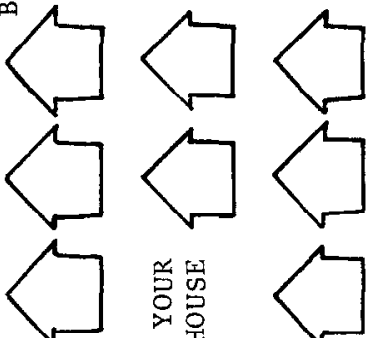

䒓留
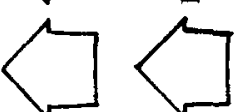

1
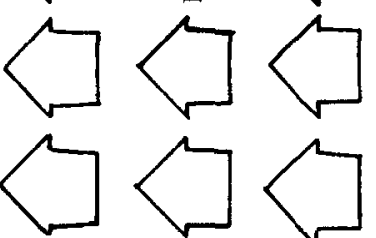

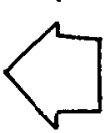

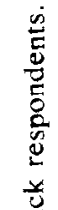

$\leftrightarrow<$

I
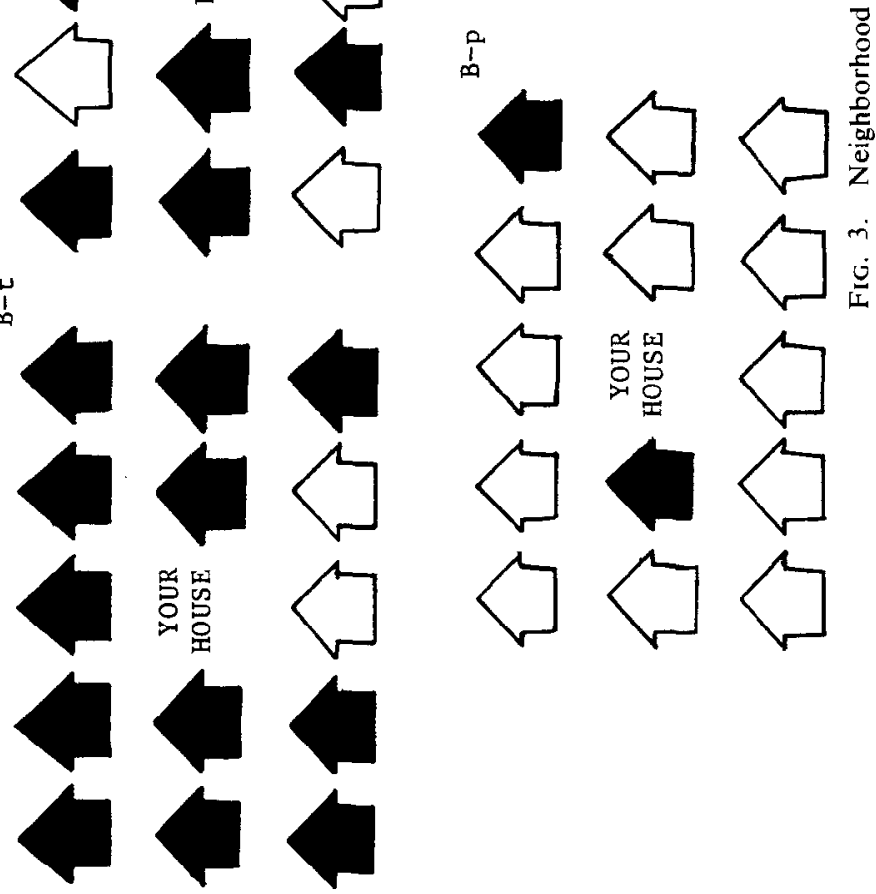

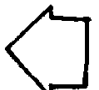

똥웡ํํㅇ

4

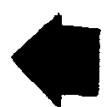

1

1

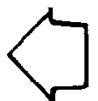

1

in 

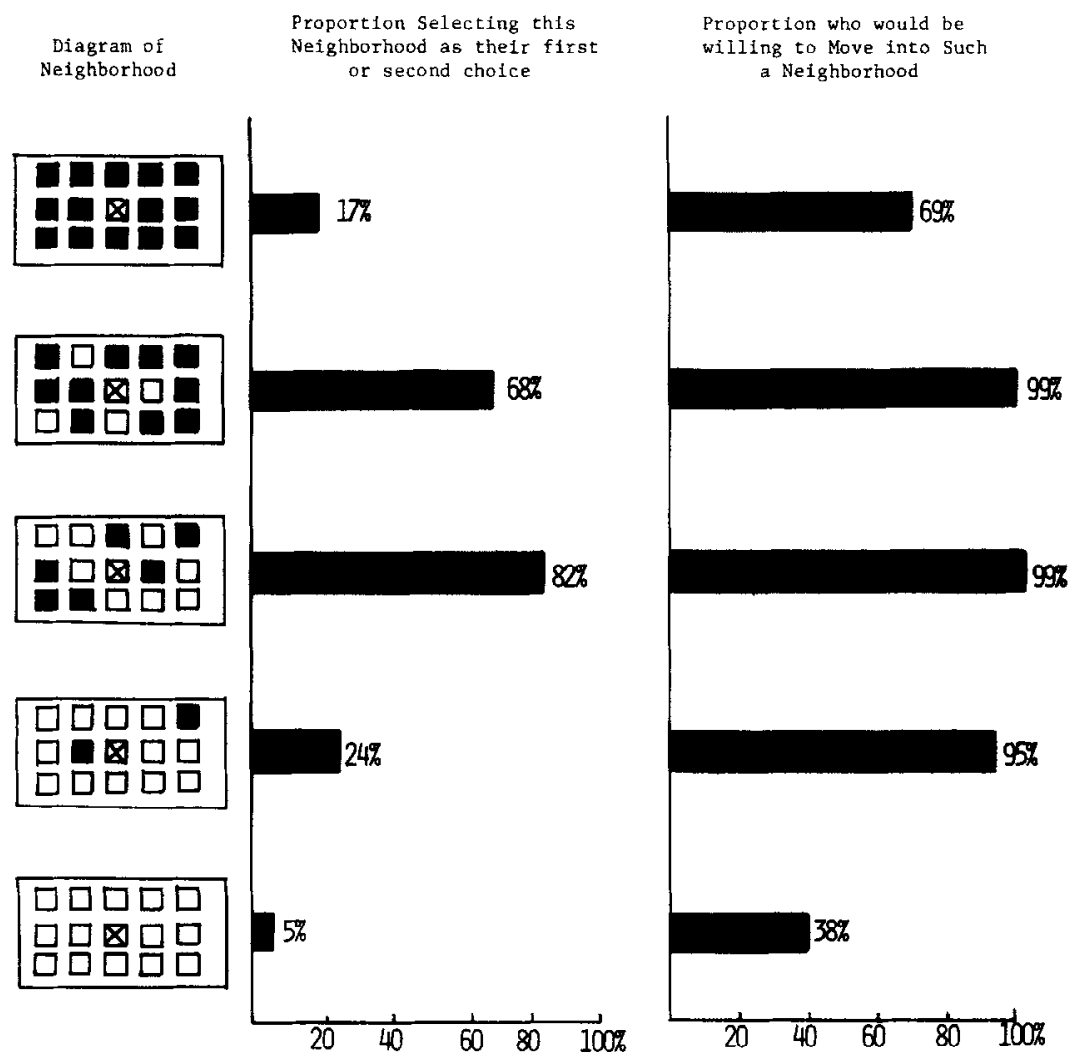

FIG. 4. Attractiveness of neighborhoods of varying racial composition for black respondents $(N=400)$.

For each type of neighborhood, we asked respondents whether they would be willing to move into it provided they found a nice house they could afford. The percentage of respondents indicating their willingness to enter these neighborhoods is shown in the right panel of Fig. 4. Almost all blacks claimed they would move into neighborhoods which contained ten, seven, or two other black residents. Opposition to all black neighborhoods seemed strong, given the pervasive residential segregation of the Detroit area which leads most blacks to live in almost exclusively black areas. Thirty-one percent of the respondents said they would not move into a nice house in an all-black neighborhood. We also used an openended question to get at their reasons for this. About one-half of the respondents cited such problems as low property values, crime, vandalism, and difficulties with children in all-black neighborhoods.

As indicated in Fig. 4, many blacks are apparently willing to be the third black family in a largely white area but are reluctant to be the first. The more than 200 blacks who would not move into an all-white area were also 
asked their reasons. Only a few gave ideological explanations concerning an explicit desire to live with other blacks. The majority-about $90 \%-$ expressed the opinion that whites in white areas would not welcome them. About one-sixth of the black respondents stated such views as "I might get burned out or never wake up," "They would probably blow my house up." A much more common view-given by more than $60 \%$ of those who would not enter an all-white area-was that whites would be unfriendly to the first black family, scrutinize their behavior, and make them feel out of place.

Our data from the residential segregation questions and from several other racial attitude questions suggest that there is no strong ideological support in the Detroit black community for separate black neighborhoods nor do most blacks express antiwhite attitudes. Freed of the fear of racial hostility, we believe that most Detroit area blacks would select neighborhoods which are about one-half white and one-half black. Their reasons for choosing such areas often involve learning to get along with whites. Almost all blacks are willing to move into integrated neighborhoods but there is considerable reluctance on the part of blacks to entering all-black areas and even greater reluctance to move into exclusively white neighborhoods.

\section{The Openness of Areas to Blacks and Their Desirability}

Blacks wish to live in racially mixed areas but many of them are fearful about moving into largely white neighborhoods. We wondered if blacks viewed all white residential areas as equally hostile to them or if they differentiated the locations and realized that they might be welcome in some places but not in others.

We once again showed respondents the map of the Detroit area (Fig. 1) and asked them: If a black family moved into each area, would the family be welcome or would whites who already lived there be upset? The left panel of Fig. 5 reports the proportion of respondents who thought that white families in each area would be upset if a black family moved there.

The one area which is experiencing racial transition is northwest Detroit. Blacks define it as the most "open" of the areas and believe that few whites would be upset if more blacks entered that area. They do not view the suburbs as an undifferentiated mass for they realize that blacks are more likely to receive a friendly welcome in Southfield-the most expensive suburb-or Taylor-the least expensive, than in Dearborn or Warren.

We wondered if views about the openness of areas to blacks were widely shared in the Detroit area or if blacks and whites had different information about this aspect of the housing market. Whites were asked their opinions about the reception blacks would receive and these are also reported in Fig. 5. Almost all whites think that blacks who move into the 


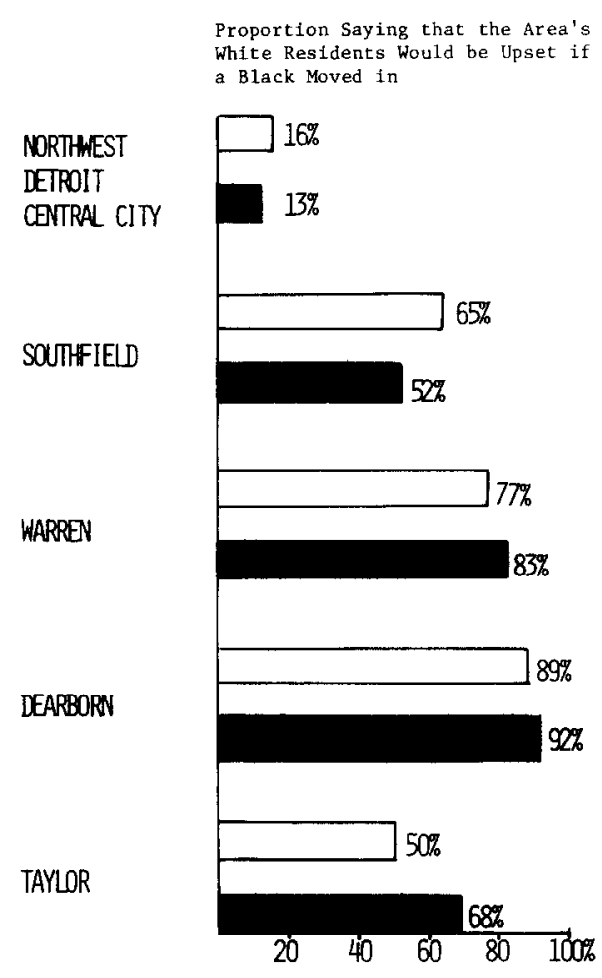

Proportion Indicating the Area is a Desirable Place to Live Black Moved in

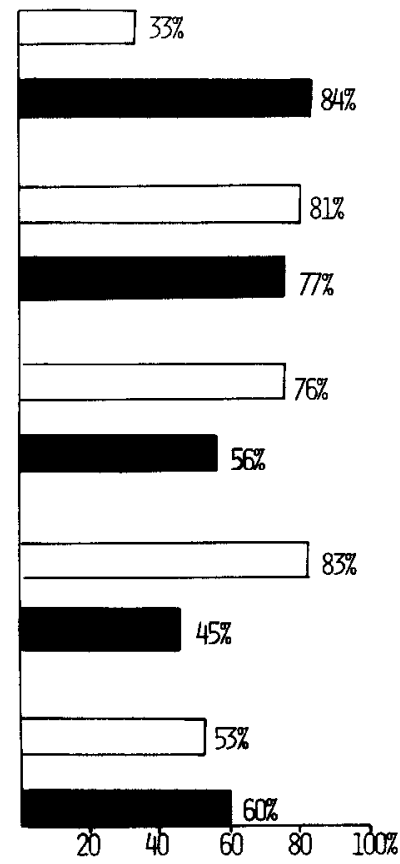

FIG. 5. Proportion of Detroit area blacks (dark bar) and whites (clear bar) who view various areas as open to blacks or a desirable place to live.

northwest section of the city will be welcomed and that the white residents of Dearborn would be exceptionally inhospitable to blacks. This suggests that information about where blacks can live is widely known by both races.

We wished to determine if blacks who saw an area as "open" to them also tended to believe that it is a desirable place to live. Respondents were asked to look at the map and rank each location on a four-point scale ranging from very desirable to very undesirable. The panel on the right in Fig. 5 reports the proportion who indicated the location and was a somewhat or a very desirable place to live.

Among both races, we find a strong correspondence between the perceived openness of an area to blacks and its desirability. Blacks see Dearborn as the most hostile location and rank it as the least desirable. Whites, on the other hand, see it as least open to blacks and rank it most desirable.

The most striking racial difference is the evaluation of the northwest section of the central city. Blacks view this as the area where they would experience little white hostility and rank it as most desirable but whites 
see it as very much less desirable than any of the suburbs. Recall that this area was more than $99 \%$ white in 1970 and, although some racial transition has occurred, it is still predominantly white. More than $80 \%$ of the respondents in our 1976 cross-sectional survey who lived in or near this area were white. We asked white respondents what they thought the racial composition of this area was and $85 \%$ believed that it was currently at least half black. Whites erroneously think of this section of the city as black and this probably explains their low evaluation of it.

Blacks and whites in the Detroit area share the same views of which areas will give blacks a friendly or hostile reception. However, they have very different opinions about the desirability of various areas. Blacks tend to see as most desirable those locations which are open to them whereas whites see areas open to blacks as undesirable. The areas they think most desirable are those closed to black residents.

\section{HOW MUCH RESIDENTIAL INTEGRATION WILL WHITES ACCEPT?}

Residential segregation depends not only upon the willingness of blacks to enter largely white areas but the willingness of whites to remain in or enter neighborhoods where there are already black residents. The residential preferences of whites were studied in a manner similar but not exactly identical to that used with black respondents.

Each white respondent was presented with a series of five diagrams showing 15 homes (see Fig. 6). We asked them to imagine that they lived in an all-white area similar to that shown on the first card, using the center house as theirs. Next, they were asked to imagine that a black family moved into the neighborhood. At this point, they were shown the second card which indicates one home occupied by blacks and 13 by whites. White respondents were asked how comfortable they would be in that neighborhood. They were then shown the third card which indicated that three black families lived in the neighborhood; a fourth card with five black families and, finally, a fifth card which portrayed a neighborhood of eight black and six white families. In pretests, we experimented with cards showing even higher densities of blacks but almost no whites felt comfortable in such neighborhoods.

The left panel of Fig. 7 shows the proportion of white respondents who said they would be uncomfortable in each neighborhood. White resistance to mixed neighborhoods is very evident. Even in the situation of minimum integration-one black and 14 white families-one-quarter of the whites claimed they would be uncomfortable. As the proportion black rose, so too did discomfort among whites. In a neighborhood which was half black, $72 \%$ of the whites said they would be uncomfortable.

We asked those white respondents who reported being uncomfortable in a neighborhood whether they would actually try to move out. In the middle panel of Fig. 7 we report the proportion who said they would 
3

$<$

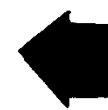

$\infty$

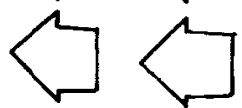

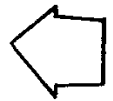

象骂

1

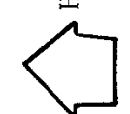

$r$

1
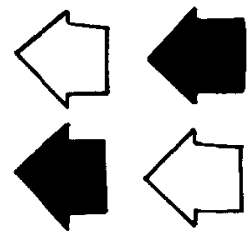

$r$

3
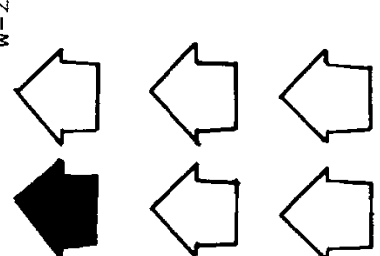

1

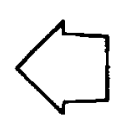

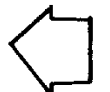

采卷

1

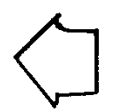

1

$\infty_{\infty}$

3

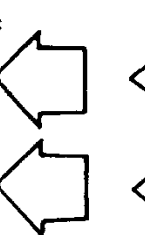

$1<$

$\sim$

1

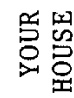

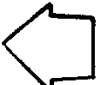

$\checkmark$

$\square$

$\frac{3}{3}$

$\frac{1}{3}$

1

$r$

$\checkmark$

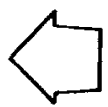
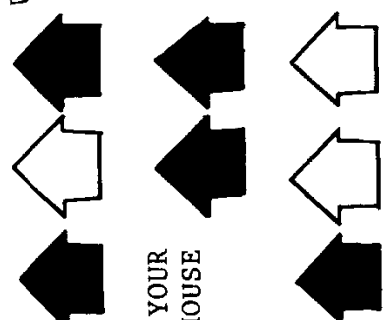

오ㅇㅝㅗㅇㅝㅗ
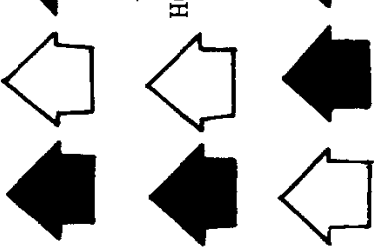

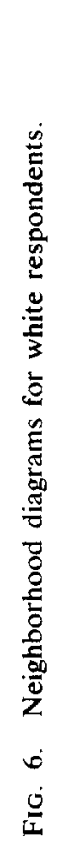
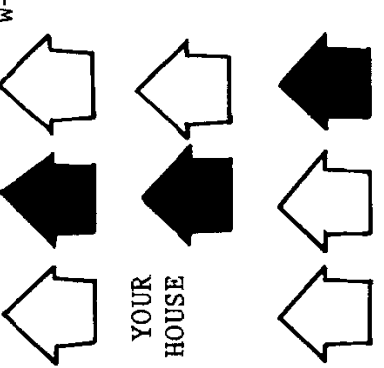

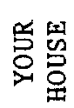<smiles>CC1CCCC1</smiles><smiles>C1CCCC1</smiles>

$r$
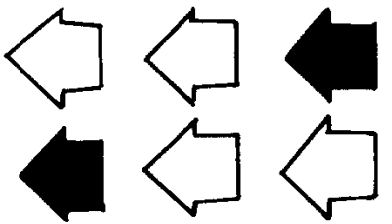


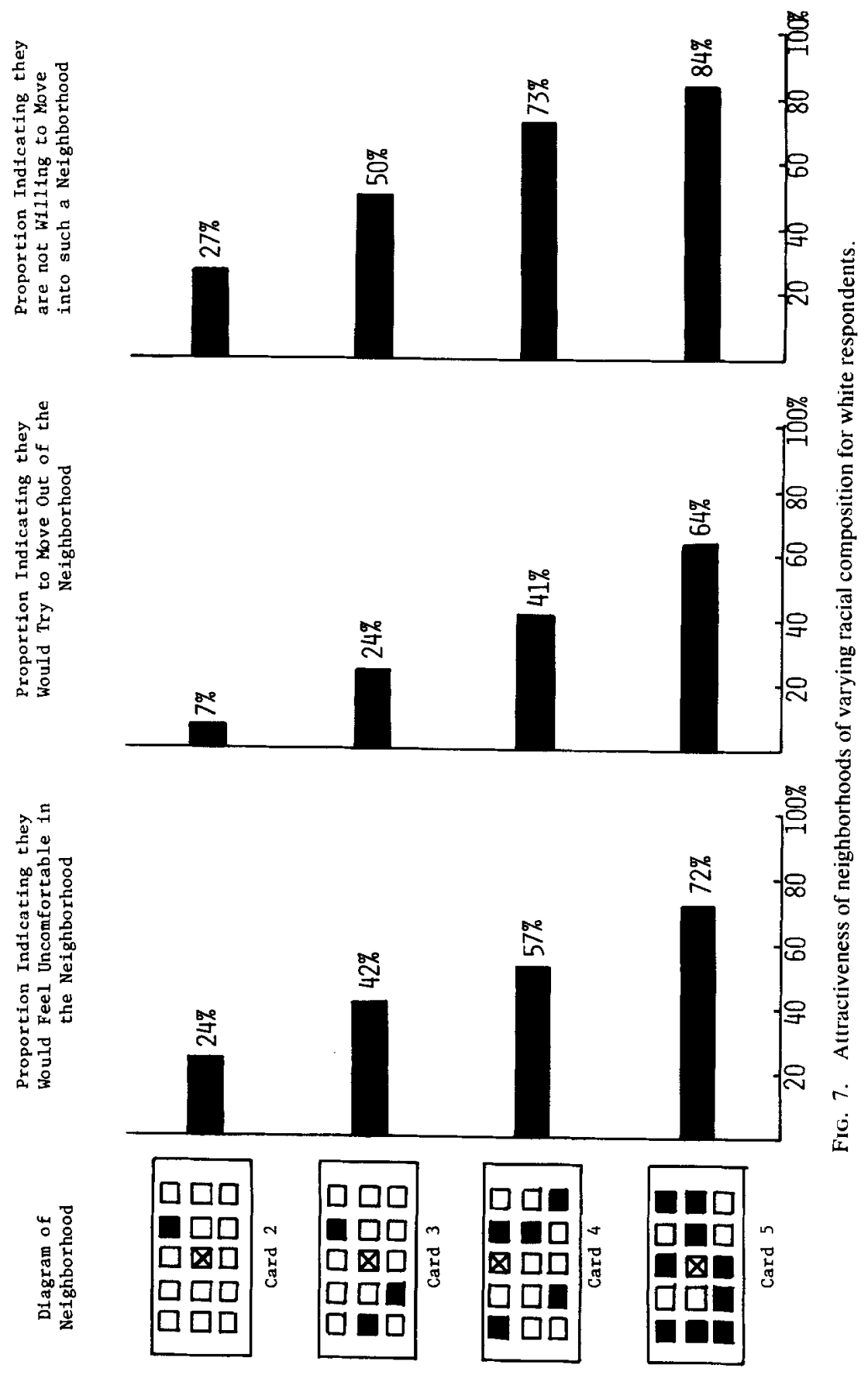


attempt to leave each neighborhood. This proportion is quite low for the neighborhood which contains one black family-only $7 \%$ of the whites would try to leave-but increases rapidly. Forty percent say they would move away from a neighborhood which is one-third black and $64 \%$ would leave the majority black area.

The more than 400 white respondents who said they would move away from one of the neighborhoods were asked why they would do so. The modal explanation focused upon property values. That is, about $40 \%$ of the whites believed that the entry of blacks was tantamount to depreciating property values. The most common reasons were "They don't care about anything they own," and "Because if I stayed longer, my home wouldn't be worth anything." The next most common explanation had to do with crime and safety. Some white respondents contended that crime rates in any area are directly proportional to the black population and that if there were many blacks, they would fear for their personal safety. A related theme was reported by many whites who said they would feel out of place if they lived in a majority black neighborhood.

As a final question concerning residential preferences white respondents were asked to imagine they had been looking for a home and had found a nice one they could afford. The house could be located in the several types of neighborhoods shown on the cards presented to them. We asked them which neighborhoods they would consider moving intu. The third panel of Fig. 7 shows the proportion of whites who would not consider moving into each type of neighborhood.

The willingness of whites to enter a neighborhood is, as anticipated, inversely proportional to the representation of blacks in that area. However, there is some opposition to entering even the minimally integrated area. More than one-quarter of the whites said they would not consider a nice home they could afford if the area contained one black and 13 whites. Looking across Fig. 7, we observe that if there are three blacks in the neighborhood, more than $40 \%$ of the whites would be uncomfortable, about one-quarter would try to move out, and one-half of the whites would not consider moving into such an area.

\section{Tipping Points and Neighborhood Transition}

There is a good deal of variation in the neighborhood preferences of the white respondents. While the majority of whites would not remain in a neighborhood that is mostly black, there are many whites who are willing to tolerate some representation of blacks in their neighborhoods. In evaluating the consequences of the preferences of whites for future trends in residential integration, it is appropriate to consider the distribution of white preferences in greater detail. Figure 8 shows the cumulative proportion of whites who would try to move out of and who would be willing to move into various neighborhoods. The horizontal axis corresponds to the 


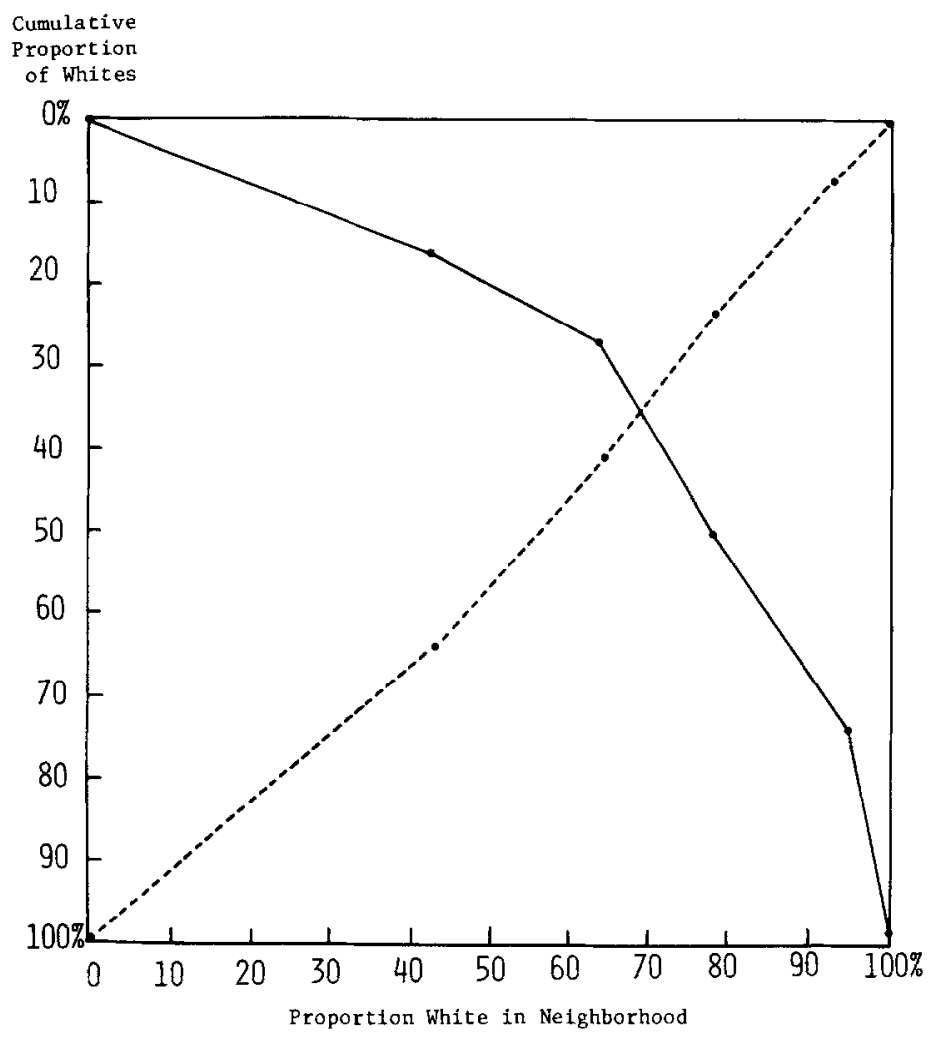

Cumulative proportion who would be willing to move in.

Cumulative proportion of whites who would try to move away.

Fig. 8. Cumulative proportion of Detroit area whites who would try to move out or who would be willing to move into neighborhoods with designated racial mixes.

proportion white residing in a hypothetical neighborhood. The vertical axis is the proportion of whites who say they would move into or away from each of the four neighborhoods pictured on our cards (see Fig. 6). In plotting these proportions for the entire range of hypothetical neighborhoods, we assumed that all whites would feel uncomfortable and would try to move out of a nearly all black neighborhood and that none would be uncomfortable in an all-white neighborhood. The scale for these proportions along the vertical axis runs from $0 \%$ at the top to $100 \%$ at the bottom.

We can consider the point where the curve representing the proportion of whites who would move out intersects with the curve representing the proportion of whites who would enter the neighborhood to be a "tipping point." That is, all points to the left of this point along the horizontal axis 
have fewer whites willing to move in than who say they would move out. We conceptualize this as a tipping point hecause as the proportional representation of blacks in a neighborhood increases beyond this point, the transition to an all black neighborhood is likely to accelerate. More whites begin to feel uncomfortable and try to move out and there are fewer and fewer whites who are willing to replace them in a neighborhood with such a large representation of blacks. ${ }^{3}$

According to Fig. 8, we can define a $70 \%$ white $30 \%$ black neighborhood as the tipping point. This point represents the intersection of the "move out" and "move in" curves for whites. This seems to imply that neighborhoods with greater than $70 \%$ white will remain stably integrated. For example, consider the point on the horizontal axis which represents a neighborhood which is $93 \%$ white-one black and 14 whites. We find that $76 \%$ of the whites would consider moving into such an area and only $7 \%$ would try to leave. We expect that such an area might remain racially mixed for there are many whites willing to move in and replace those other whites who would leave. However, we know that stable integrated neighborhoods are rarely found in American cities (Taeuber and Taeuber, 1965, Chap. 5; Duncan and Duncan, 1957, pp. 99 and 120). Schelling (1971, 1972) determined through the use of mathematical models that if the residential preferences of the white residents of a neighborhood differ, the dynamics of the situation will drive the proportion black successively over each individual's maximum tolerance and the neighborhood will ultimately become a black residential area. That is, although there are more whites who would move into a 93\% white neighborhood than move out, if any of the vacancies created by the exodus of whites are filled by blacks-and almost all Detroit area blacks would consider moving into that type of neighborhood-some additional whites who were comfortable will become uncomfortable with the new racial composition. They may' move and create new vacancies which may be filled by blacks. Therefore the proportion black will rise and other whites may decide to leave. As Schelling has demonstrated theoretically, it is precisely the variance that we observe in the neighborhood preferences of whites that causes neighborhoods to change from all white to all black. However, until the distribution of preferences by neighborhood is considered it is difficult to determine if this pattern of neighborhood change is inevitable in Detroit. ${ }^{4}$

${ }^{3}$ Of course, given the proportional representation of blacks and whites in the metropolitan area, the actual supply of whites who would move into many neighborhoods (even those that are less than $70 \%$ white) is likely to be larger than the supply of blacks. For this reason, the "tipping point" indicated in Fig. 8 should more realistically be represented somewhat more to the left.

${ }^{4}$ To get a realistic picture of the stability of neighborhoods it would also be necessary to take into account other factors which determine the operation of the housing market. 


\section{THE PROSPECTS FOR RESIDENTIAL INTEGRATION}

When we consider the residential preferences of whites in the Detroit area, the prospects for residential integration seem quite slim. Many whites are willing to tolerate some degree of racial integration in their neighborhoods, but the variance in white preference indicates that stable neighborhood integration is unlikely to occur. While the neighborhood preferences of blacks are considerably more favorable to residential integration than the preferences of whites-the overwhelming majority of blacks chose an integrated neighborhood as the one that is most attractive to them-even these data must be interpreted with a certain amount of pessimism. Since neighborhoods with equal numbers of black and white residents are not widely available and because there is a strong aversion to all white neighborhoods, many blacks who state a preference for integrated neighborhoods may actually choose to live in largely black areas.

Consideration of data about the knowledge that blacks and whites have of the Detroit area housing market also leads to the conclusion that the prospects for residential integration are not good. We speculate that both blacks and whites are very knowledgeable about where they and the other race "belong" and that real estate marketing practices reinforce these judgments primarily by steering blacks and whites to separate areas. For instance, our investigation finds that almost all Detroit area residents are aware of the antiblack reputation of Dearborn and, we presume, few blacks would try to enter that suburb. Whites, on the other hand, define the northwest corner of the central city as black and probably do not seek housing there even if it is readily available at an attractive price. We presented the following hypothetical situation to all respondents.

"I'd like you to imagine that you're going to move. You have a choice of buying two houses that are identical, except that one is located in northwest Detroit and the other is located in a desirable suburb. The house in the suburb costs $\$ 8000$ more than the house in Detroit. Which of the two houses would you choose to move into?"

Given these alternatives, $90 \%$ of the whites selected the suburban home while $75 \%$ of the blacks selected the one in the city. Although endorsing the ideal of residential integration and expressing some willingness to live in racially mixed areas, we believe that many whites would actually spend large sums of money to avoid living in an area which they believe "belongs" to blacks such as the northwest section of the central city.

Blacks are equally knowledgable about housing costs and the openness of various areas to them. They realize that whites in each of the suburbs would be more upset by their entry than whites in the central city. For these reasons many blacks who endorse the ideal of integrated housing 
may avoid the suburbs and seek homes in those parts of the city which are now undergoing racial transition.

These data indicate that the likelihood of achieving stably integrated neighborhoods in the Detroit area is small. However, before issuing such a dismal pronouncement, it is appropriate to consider other factors which may reduce residential segregation. Whites vary in their tolerance for living with blacks and some blacks are more willing than others to enter white neighborhoods. We wondered if we could identify groups of the population who were favorable to integration and whether this might portend an eventual reduction in residential segregation. Perhaps young and well-educated blacks and whites have residental preferences which will lead to integration.

For each white respondent we defined a residential preference score based upon his or her ordering of the cards showing various interracial neighborhoods. Scores ranged from 0 -low acceptance of racial residental integration-to 40-high acceptance of such integration. For blacks, a similar but not identical scoring system was devised with values ranging from 5-low acceptance of residential integration-to 40 (Colasanto, 1977, Chap. 4).

Table 3 presents the outcome of this analysis. The racial residential preference score is the dependent variable while the independent variables are age, educational attainment, family income, and residential closeness to the other race. The analytic technique of multiple classification analysis (MCA) has been used. For each category of every independent variable, the gross deviation from the overall mean is shown. That is, white respondents had an average racial residential preference score of 24.7; those under age 31 were slightly more favorable to integration and had a score averaging 0.2 points higher than the overall average. A net difference is also presented which is the deviation from the overall average once the effects of all other variables have been taken into account. The MCA model indicates the variance in racial residential preference accounted for singularly by each independent variable and by the entire collection of explanatory variables (Andrews, Morgan, and Sonquist, 1969).

Racial residential preferences are very weakly linked to these background variables. Among both races, age is inconsistently related to residential preferences and thus we cannot conclude that young people are more willing to live in mixed areas than are the old. Among both blacks and whites, education is positively related to the acceptance of residential integration but the differences are small. Among whites, family income appears inversely related to a tolerance of black neighbors whereas among blacks, it is the richer who have stronger preferences for mixed areas but the income differences are not significantly different from zero. We find that those who live on a block with members of the other 
TABLE 3

Multiple Classification Analysis Relating Racial Preferences to Background Variables

\begin{tabular}{|c|c|c|c|c|}
\hline & \multicolumn{4}{|c|}{ Deviations from grand mean } \\
\hline & \multicolumn{2}{|c|}{ White $^{a}$} & \multicolumn{2}{|c|}{ Black $^{b}$} \\
\hline & Gross & Net & Gross & Net \\
\hline \multicolumn{5}{|l|}{ Age } \\
\hline Less Than 31 & +.2 & -.3 & -1.5 & -1.7 \\
\hline 31 to 40 & -.2 & +.4 & +.1 & -.5 \\
\hline 41 to 50 & +.9 & +1.9 & +1.1 & +.8 \\
\hline 51 to 60 & +3.1 & +3.9 & +.6 & +1.0 \\
\hline 61 or Over & -4.0 & -5.8 & +.5 & +1.8 \\
\hline Variance explained & $1.3 \%$ & & $0.8 \%$ & \\
\hline \multicolumn{5}{|l|}{ Educational attainment } \\
\hline 12 Years & -2.0 & -3.1 & -.9 & -.9 \\
\hline 12 Years & -.8 & -1.0 & +.7 & +1.0 \\
\hline 12 Years & +2.6 & +3.7 & +.9 & +.5 \\
\hline Variance explained & $0.9 \%$ & +3.7 & $0.7 \%$ & \\
\hline \multicolumn{5}{|l|}{ Family income in 1975} \\
\hline Under $\$ 5000$ & +.3 & +3.5 & -1.5 & -1.1 \\
\hline$\$ 5000$ to 11,999 & +2.4 & +4.2 & -.7 & -.5 \\
\hline$\$ 12,000$ to 19,999 & -1.4 & -1.6 & +.6 & +.3 \\
\hline$\$ 20,000$ to 29,999 & -1.3 & -3.3 & +2.7 & +2.2 \\
\hline$\$ 30,000$ or More & -.3 & -2.8 & +3.4 & +2.4 \\
\hline Variance explained & $0.7 \%$ & & $2.0 \%$ & \\
\hline \multicolumn{5}{|l|}{ Residential closeness to other race } \\
\hline On the block & +2.2 & +2.1 & +.7 & +.6 \\
\hline 1 to 3 blocks & +.6 & -.0 & -1.8 & -1.8 \\
\hline 4 to 8 blocks & -1.6 & -1.4 & -2.1 & -2.1 \\
\hline More than 8 blocks & -.3 & -.2 & -.8 & -.4 \\
\hline Variance explained & $0.4 \%$ & & $1.0 \%$ & \\
\hline Overall Mean & 24.7 & & 19.1 & \\
\hline SD & 19.7 & & 10.5 & \\
\hline $\begin{array}{l}\text { Variance explained by overall } \\
\text { model adjusted for df }\end{array}$ & & $2.9 \%$ & & $0.7 \%$ \\
\hline$N$ & 725 & & 389 & \\
\hline
\end{tabular}

a This is an index of the racial residential preferences of whites based upon their responses to cards showing neighborhoods of differing racial compositions. Possible scores range from 0-low acceptance of racial residential integration-to 40-high acceptance of such integration.

${ }^{b}$ This is an index of the racial residential preferences of blacks based on their responses to cards showing neighborhoods of differing racial compositions. Possible scores range from 5-low acceptance of racial residential integration-to 40 -high acceptance of such integration.

" $F$ test indicates that with a one-way analysis of variance models, the relationship is significantly different from 0 to .05 level of significance. 
race have somewhat higher scores on this measure of racial residential preferences but once again the differences are not significant.

We believe that residential preferences are not strongly or substantially related to these or to other background factors and thus we were unable to identify groups of the white or black population who have distinct residential preferences. There seems to be little hope that attitudes about neighborhood integration will change rapidly because of increases in educational attainment or because "conservative" older whites are replaced by "liberal" younger persons. However, it is possible that the preferences of whites and blacks can change for other reasons. Just as the attitudes of whites about school integration and the integration of public facilities are much more liberal now than before the federal government began to take action against these types of segregation, so the attitudes of whites about neighborhood integration may change rapidly as blacks begin to be more dispersed in the metropolitan area. Until we know more about the sources of these preferences for whites and blacks, it is difficult to specify what kind of changes are likely to occur in the distribution of neighborhood preferences.

\section{SUMMARY AND CONCLUSION}

This study moved beyond previous investigations of the causes of racial residential segregation. By the use of improved measures of knowledge, beliefs, and attitudes, we addressed three questions.

(i) Is racial residential segregation largely the result of misperceptions about the ability of blacks to afford housing in the Detroit area?

(ii) Is residential segregation mainly the result of black preferences for segregated neighborhoods?

(iii) Is residential segregation mainly the result of white preferences for segregated neighborhoods?

Turning to the first question, our study analyzed a subjective version of the economic hypothesis. We discovered that both blacks and whites were quite knowledgable about the costs of housing in various parts of the Detroit area. They also correctly perceive that many blacks can afford to live in attractive white areas. We reject the idea that ignorance of the housing market is responsible for racial residential segregation.

With regard to the second question, we find that black preferences as a cause of residential segregation finds credence only in the attributions of whites themselves. When asked why there was such extensive residential segregation, whites often said that "Birds of a feather flock together" or that "Blacks try to stick with their own kind." However, most black respondents expressed a preference for mixed neighborhoods. Whites dramatically underestimate the willingness of blacks to live in racially mixed areas, perhaps because they themselves seldom wish to live in such neighborhoods. 
The preferences of whites for neighborhoods that do not include many blacks are one important source of the maintenance of high levels of residential segregation. ${ }^{5}$ Through the use of carefully constructed sets of measures, this study demonstrates what other investigations of attitudes toward racial residential segregation have failed to show-that whites are not very accepting of residential integration. This investigation replicated two items which have been used in several studies of white attitude change which show steady improvement in the acceptance of integration-the "Black on your block" and "Would you sell to a black" questions. If we had asked just these questions, we would have concluded that there was a wide-spread acceptance of residential integration on the part of Detroit area whites. This would have been contrary to the objective evidence. Our techniques-the use of diagrams of mixed neighborhoods-allowed respondents to go beyond reacting to general values and move toward how they would personally feel in specific situations, what they would actually do, and why. For this mode of inquiry, we obtained a different picture-one closer to the "reality" of high levels of racial residential segregation.

\section{REFERENCES}

Andrews, F., Morgan, J., and Sonquist, J. (1969), Multiple Classification Analysis, Institute for Social Research, University of Michigan, Ann Arbor.

Bianchi, S. M. (1976), "Sampling Report for the 1976 Detroit Area Study," Detroit Area Study, University of Michigan, Ann Arbor. unpublished.

Campbell, A. and Schuman, H. (1968), Racial Attitudes in Fifteen American Cities, Institute for Social Research, University of Michigan, Ann Arbor.

Colasanto, D. (1977), The Prospects for Racial Integration in Neighborhoods: An Analysis of Residential Preferences in the Detroit Metropolitan Area, Ph.D. Dissertation, University of Michigan.

Duncan, O. D., and Duncan, B. (1957), The Negro Population of Chicago, University of Chicago.

Duncan, O. D., Schuman, H., and Duncan, B. (1973). Social Change in a Metropolitan Community, Russell Sage, New York.

Hermalin, A. I., and Farley, R. (1973), "The potential for residential integration in cities and suburbs: Implications for the busing controversy," American Sociological Review 38, 595-610.

Levine, R. A. (1971-72), "The silent majority: Neither simple nor simple-minded," Public Opinion Quarterly 35, 571-577.

Levitan, S. A., Johnston, W. B., and Taggart, R. (1975), Still a Dream: The Changing Status of Blacks since 1960, Harvard Univ. Press, Cambridge, Mass.

Long, L. H. (1975), "How the racial composition of cities change," Land Economics LI, 258-267.

${ }^{5}$ In this paper we have considered only those factors which relate to individual preferences and perceptions as causes for residential segregation. The fact that these preferences are important does not imply that other factors (i.e., structural factors, discrimination) are not important. In fact, it is quite likely that structural factors and individual factors may be associated and are jointly responsible for the high levels of segregation observed in urban areas. 
Malbix/Ricks Music, BMI (1976). "Chocolate City." available on Casablanca Records, NBLP 7014.

National Opinion Research Center (1972), National Data Program for the Social Sciences, Spring, 1972 (General Social Survey). National Opinion Research Center, University of Chicago.

Pcttigrew, T. F. (1973), "Attitudes on race and housing: A social-psychological view," in Segregation in Residential Areas (A. H. Hawley and V. P. Rock, Eds.), Natl. Acad. Sci., Washington, D.C.

Schelling, T. C. (1971), "Dynamic models of segregation." Journal of Mathematical Sociology $1,148-186$.

Schelling, T. C. (1972), "A process of residential segregation: Neighborhood tipping," in Racial discrimination in Economic Life (A. H. Pascal, ed.). Heath, Boston.

Sheatsley, P. B. (1966), "White attitudes toward the negro," Daedalus 95, 217-238.

Sørensen, A., Taeuber, K. E., and Hollingsworth, L. J., Jr. (1975). "Indexes of racial residential segregation for 109 cities in the United States. 1940 to 1970," Sociological Focus 8, 125-142.

Taeuber, K. E., and Taeuber, A. F. (1965), Negroes in Cities. Aldine, Chicago.

U.S. Bureau of the Census (1962), Census of Population: 1960, PC(1)-24C.

U.S. Bureau of the Census (1971a) Census of Population: 1970, PC(1)-B24.

U.S. Bureau of the Census (1971b), Census of Housing: 1970, HC(1)-A24.

U.S. Bureau of the Census (1972a), Census of Population: 1970, PC(1)-C24.

U.S. Bureau of the Census (1972b), Census of Population and Housing: 1970, PHC(1)-58.

U.S. Bureau of the Census (1973), Census of Population: 1970, PC(2)-60.

U.S. Bureau of the Census (1975), Current Population Reports, Series P-20, No. 285.

U.S. Bureau of the Census (1976). Annual Housing Survey: 1974. Series H-170-74-5.

U.S. National Advisory Commission on Civil Disorders (1969), Report of the National Advisory Commission on Civil Disorders, Government Printing Office, Washington.

U.S. Office for Civil Rights (1977), Directory of Public Elementary and Secondary Schools in Selected Districts, Enrollment and Staff by Racial/Ethnic Groups, Tape File.

Van Valey, T., Roof. W. C. and Wilcox. J. E. (1977), "Trends in residential segregation: 1960-1970," American Journal of Sociology 82, 826-844. 